\title{
Fibrocyte accumulation in the airway walls of COPD patients
}

\author{
Isabelle Dupin (10) $1,2,4$, Matthieu Thumerel (10) ${ }^{1,2,3,4}$, Elise Maurat ${ }^{1,2}$, \\ Florence Coste (10) ${ }^{1,2}$, Edmée Eyraud ${ }^{1,2}$, Hugues Begueret ${ }^{3}$, Thomas Trian ${ }^{1,2}$, \\ Michel Montaudon ${ }^{1,2,3}$, Roger Marthan ${ }^{1,2,3}$, Pierre-Olivier Girodet ${ }^{1,2,3}$ and \\ Patrick Berger (10) $1,2,3$
}

Affiliations: 'Université Bordeaux, Centre de Recherche Cardio-thoracique de Bordeaux, U1045, Département de Pharmacologie, CIC 1401, Bordeaux, France. ${ }^{2}$ INSERM, Centre de Recherche Cardio-thoracique de Bordeaux, U1045, CIC 1401, Bordeaux, France. ${ }^{3} \mathrm{CHU}$ de Bordeaux, Service d'Exploration Fonctionnelle Respiratoire, Service de Chirurgie Thoracique, Service d'Anatomopathologie, Service de Radiologie, CIC 1401, Pessac, France. ${ }^{4}$ These two authors contributed equally to this work.

Correspondence: Isabelle Dupin, Université Bordeaux, Centre de Recherche Cardio-thoracique de Bordeaux, U1045, PTIB, Hôpital Xavier Arnozan, Avenue du Haut-Lévêque, 33604 Pessac, France.

E-mail: isabelle.dupinau-bordeaux.fr

@ERSpublications

A high density of tissue fibrocytes is associated with reduced lung function and an increase in airway wall thickness bit.ly/2JO71Dq

Cite this article as: Dupin I, Thumerel M, Maurat E, et al. Fibrocyte accumulation in the airway walls of COPD patients. Eur Respir J 2019; 54: 1802173 [https://doi.org/10.1183/13993003.02173-2018].

ABSTRACT The remodelling mechanism and cellular players causing persistent airflow limitation in COPD remain largely elusive. We have recently demonstrated that circulating fibrocytes, a rare population of fibroblast-like cells produced by the bone marrow stroma, are increased in COPD patients during an exacerbation. We aimed to quantify fibrocyte density in situ in bronchial specimens from both control subjects and COPD patients, to define associations with relevant clinical, functional and computed tomography (CT) parameters, and to investigate the effect of the epithelial microenvironment on fibrocyte survival in vitro ("Fibrochir" study).

A total of 17 COPD patients and 25 control subjects, all requiring thoracic surgery, were recruited. Using co-immunostaining and image analysis, we identified CD $45^{+} \mathrm{FSP}^{+}$cells as tissue fibrocytes, and quantified their density in distal and proximal bronchial specimens. Fibrocytes, cultured from the blood samples of six COPD patients, were exposed to primary bronchial epithelial cell secretions from control subjects or COPD patients.

We demonstrate that fibrocytes are increased in both distal and proximal tissue specimens of COPD patients. The density of fibrocytes is negatively correlated with lung function parameters and positively correlated with bronchial wall thickness as assessed by CT scan. A high density of distal bronchial fibrocytes predicts the presence of COPD with a sensitivity of $83 \%$ and a specificity of $70 \%$. Exposure of fibrocytes to COPD epithelial cell supernatant favours cell survival.

Our results thus demonstrate an increased density of fibrocytes within the bronchi of COPD patients, which may be promoted by epithelial-derived survival-mediating factors.

This article has supplementary material available from erj.ersjournals.com

This study is registered at ClinicalTrials.gov with identifier number NCT01692444.

Received: 14 Nov 2018 | Accepted after revision: 28 May 2019

Copyright OERS 2019 


\section{Introduction}

COPD is characterised by chronic persistent inflammation and remodelling leading to progressive airflow limitation [1,2]. The evolution of this chronic disease is worsened by acute exacerbations, frequently triggered by viral or bacterial infections [3]. These exacerbations are considered an independent prognostic factor for mortality [4]. Current pharmacological treatments for COPD patients decrease exacerbation frequency by only up to $29 \%$ compared with placebo either alone or in combination, but they do not have any significant effect on mortality [5-9]. COPD patients exhibit remodelling processes leading to permanent changes in tissue structure, such as epithelial mucous metaplasia, parenchymal destruction (i.e. emphysema) and connective tissue deposition in the small airway walls [1]. The latter, also called peribronchiolar fibrosis, has been observed even in young smokers [10], thus suggesting that it may be an initiating event in COPD pathophysiology. These processes are not inhibited or reversed by current pharmacotherapy.

Fibrocytes are fibroblast-like cells produced by the bone marrow stroma and released in the peripheral circulation [11]. Circulating fibrocytes, defined as $\mathrm{CD}_{4} 5^{+}$collagen $\mathrm{I}^{+}$cells, are increased in COPD patients only during an exacerbation and not in a stable state, compared with those in control subjects [12, 13]. A high blood fibrocyte concentration during an exacerbation is associated with an increased risk of death [12], suggesting a deleterious role of fibrocytes in COPD evolution. In contrast, myeloid-derived suppressor cell-like fibrocytes, a subpopulation of circulating fibrocytes, are increased in the blood of stable COPD patients and these cells might play a protective role [13]. The presence and role of fibrocytes in the lungs of COPD patients remains controversial and needs to be clarified [13]. Indeed, tissue fibrocytes, defined as $\mathrm{CD}_{3} 4^{+}$collagen $\mathrm{I}^{+}$cells, have not been found in the distal airways of COPD patients and have been detected in the proximal airways of only $<50 \%$ of COPD patients [13]. However, fibrocytes are known to downregulate CD34 expression when differentiating [14]. Thus, the coexpression of CD34 and collagen I, as a defining criterion for tissue fibrocytes, may lead to fibrocyte underestimation [13]. Therefore, we define fibrocytes as cells positive for both CD45 and fibroblast-specific protein 1 (FSP1), consistent with previous reports from human and mouse lungs [15-18].

Thus, the aim of the present study was to determine the density of tissue fibrocytes (i.e. $\mathrm{CD} 45^{+} \mathrm{FSP} 1^{+}$ cells) in distal and proximal airway specimens of COPD patients compared with that in control subjects. We then evaluated the relationship between the density of tissue fibrocytes and parameters derived from lung function tests and quantitative computed tomography (CT) as well as the relationship with blood fibrocytes. Functional in vitro experiments were also performed to assess the effect of the epithelial microenvironment on fibrocyte survival.

\section{Methods}

A more detailed description of the methods is provided in the supplementary material.

\section{Study populations}

Subjects $>40$ years of age were eligible for enrolment if they required thoracic lobectomy surgery for cancer ( $\mathrm{pN} 0$ ), lung transplantation or lung volume reduction (see table E1 for individual indications). A total of 17 COPD patients with a clinical diagnosis of COPD according to the Global Initiative for Chronic Obstructive Lung Disease guidelines [2] and 25 non-COPD subjects ("control subjects") with normal lung function testing (i.e. forced expiratory volume in $1 \mathrm{~s}(\mathrm{FEV} 1) /$ forced vital capacity $(\mathrm{FVC})>0.70)$ and no chronic symptoms (cough or expectoration) were recruited from the University Hospital of Bordeaux (Bordeaux, France).

To study fibrocytes in vitro, blood samples were obtained from a separate cohort of COPD patients: the COBRA cohort (Cohorte Obstruction Bronchique et Asthme (Bronchial Obstruction and Asthma Cohort), sponsored by the French National Institute of Health and Medical Research, INSERM) (tables E4 and E6).

\section{Study design}

This clinical trial was sponsored by the University Hospital of Bordeaux. The study was registered at ClinicalTrials.gov with identifier NCT01692444 ("Fibrochir" study). The study protocol was approved by the local research ethics committee on May 30, 2012, and the French National Agency for Medicines and Health Products Safety on May 22, 2012. All subjects provided written informed consent. The study design is summarised in figure E1. Four visits were scheduled: a pre-inclusion visit to explain the study and surgery, an inclusion visit on the day of the surgery, a visit 1 month \pm 15 days after surgery, and a final visit 1 year \pm 15 days after surgery.

\section{Bronchial fibrocyte identification}

A subsegmental bronchus sample (for proximal tissue) and fragments of distal parenchyma were obtained from lung resection material at a distance from the tumour in the case of cancer. Additional proximal 
samples from the upper lobes and lower lobes were obtained from four transplant patients (patients 48 , 49, 51 and 52; table E1) to test potential differences in fibrocyte density in different lobes. The samples were embedded in paraffin, and $2.5 \mu \mathrm{m}$ thick sections were cut and stained with a rabbit anti-FSP1 polyclonal antibody (Agilent, Les Ulis, France) and a mouse anti-CD45 monoclonal antibody (BD Biosciences, San Jose, CA, USA) or a mouse anti-CD3 monoclonal antibody (Agilent), a mouse anti-CD19 monoclonal antibody (Agilent) and a mouse anti-CD34 monoclonal antibody (Agilent). The sections were imaged using a Nanozoomer 2.0HT slide scanner (Hamamatsu Photonics, Massy, France). Quantification of FSP1 and CD45 double-positive cells was performed as described in figure 1 . The density of FSP1 ${ }^{+}$ $\mathrm{CD} 45^{+}$cells was defined by the ratio between the numbers of double-positive cells in the lamina propria divided by the lamina propria area. Quantification of double-positive FSP1 and CD3, FSP1 and CD19 or FSP1 and CD34 cells was performed as described earlier with some modifications (see supplementary material). Tissue area and cell measurements were all performed in a blinded fashion.

\section{Quantitative CT}

CT scans were performed on a Somatom Sensation Definition 64 (Siemens, Erlangen, Germany) at full inspiration and expiration, and analysed using dedicated and validated software, as described previously [19-22].

\section{Circulating fibrocyte identification}

Nonadherent non-T (NANT) cells were purified from peripheral blood mononuclear cells (PBMCs) separated from the whole blood, and circulating fibrocytes were identified as cells double positive for the surface marker CD45 and the intracellular marker collagen I by flow cytometry, as described previously [12].

\section{Bronchial epithelial supernatants}

Human bronchial epithelial cells (BECs) were derived from bronchial specimens (see table E5 for patient characteristics), as described previously [23]. Basal epithelial supernatant from fully differentiated epithelium was collected for further experiments.

\section{Fibrocyte differentiation and survival}

NANT cells purified from blood samples of COPD patients (tables E4 and E6) were incubated for 1 week in DMEM (Fisher Scientific, Illkirch-Graffenstaden, France) supplemented with $20 \%$ FCS (Biowest, Riverside, MO, USA), followed by 1 week in serum-free medium or serum-free medium containing $50 \%$ basal epithelial supernatant. After 2 weeks in culture, the cells were fixed and stained for CD45, FSP1,
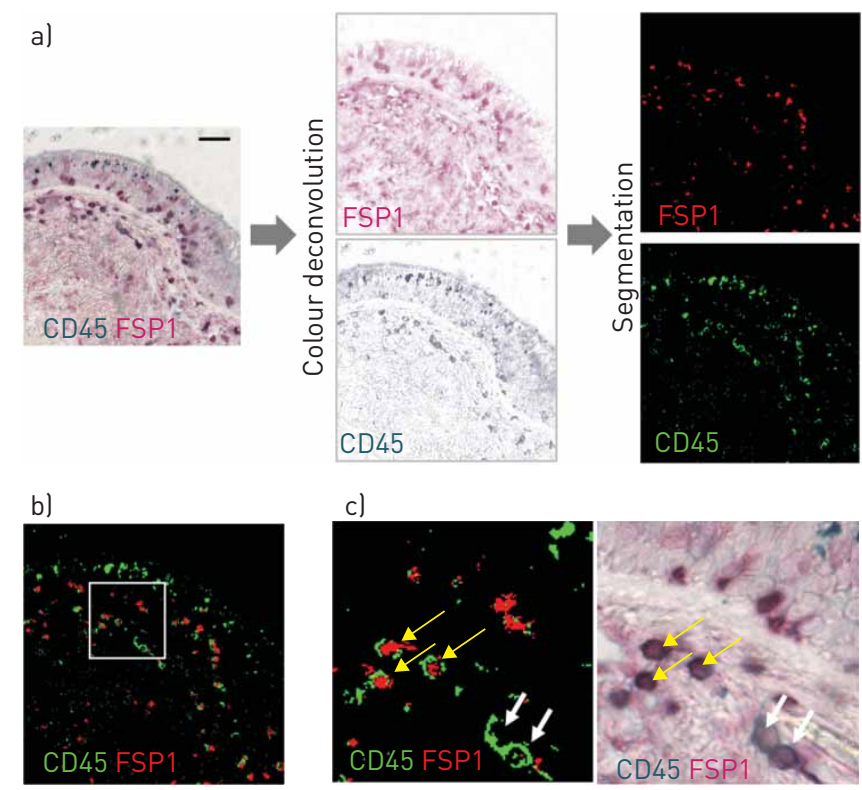

FIGURE 1 Detection of $\mathrm{CD}^{+} 5^{+}$fibroblast-specific protein 1 (FSP1) cells. a) Left column: CD45 (green) and FSP1 (red) staining; middle column: images for CD45 and FSP1 staining obtained after colour deconvolution; right column: segmented images obtained for CD45 and FSP1 staining after segmentation by a binary threshold. Scale bar: $50 \mu \mathrm{m}$. b) Merged segmented image. c) Higher magnification of the segmented image in (b). The yellow and white arrows indicate $\mathrm{CD} 45^{+} \mathrm{FSP} 1^{+}$cells and $\mathrm{CD} 45^{+}$cells, respectively. 
fibronectin, vimentin, $\alpha$-smooth muscle actin ( $\alpha$-SMA) and collagen I expression or detached by accutase (Fisher Scientific) and either fixed overnight with Cytofix/Cytoperm and stained to assess the expression of the same proteins or directly stained by propidium iodide (PI) to assess the percentage of dead cells $\left(\mathrm{PI}^{+}\right.$cells) by flow cytometry.

\section{Statistical analysis}

Values are presented as mean with standard deviation or median (95\% confidence interval). Statistical significance, defined as $\mathrm{p}<0.05$, was analysed by Fisher's exact test for the comparison of proportions, by the two-sided independent t-test for variables with a parametric distribution, and by the Wilcoxon test, Mann-Whitney U-test and Spearman's correlation coefficient for variables with a nonparametric distribution. Concerning correlation analyses, no mathematical correction was made for multiple comparisons, as previously recommended [24]. A receiver operating characteristic (ROC) analysis and a univariate logistic regression analysis were performed to evaluate the association between COPD and a high density of tissue fibrocytes.

\section{Results}

\section{Study population}

The number of patients enrolled, excluded or followed for up to 1 year after surgery is shown in figure E1. Clinical and functional characteristics together with quantitative CT parameters of all subjects with tissue fibrocyte assessment are shown in table 1. The groups of control and COPD patients were well matched for age and body mass index. As expected, COPD patients were significantly different from controls in terms of smoking habits, lung function (FEV1, FVC, FEV1/FVC ratio and residual volume (RV)), diffusing capacity (transfer factor of the lung for carbon monoxide (TLCO)) and CT parameters, including wall thickness, emphysema extent (low-attenuation area), air trapping (mean lung attenuation value during expiration), and cross-sectional pulmonary vessel area and number (table 1). The sex ratio was also different, with more males in the COPD group.

\section{Bronchial fibrocyte numbers are increased in COPD patients}

As a methodological control, we first cultured fibrocytes from blood samples from a separate cohort of COPD patients (table E4) and we showed that virtually all $\mathrm{CD} 45^{+} \mathrm{FSP} 1^{+}$cells $(99.7 \pm 0.5 \%, \mathrm{n}=9)$ purified from circulating PBMCs also express collagen I after 14 days of differentiation in vitro (figure E2). Similarly, $87.5 \pm 6.2 \%$ of $\mathrm{CD} 45^{+}$collagen $\mathrm{I}^{+}$cells were positive for FSP1 staining in the same culture conditions ( $\mathrm{n}=9)$. $\mathrm{CD}_{4} 5^{+} \mathrm{FSP}^{+}$cells spontaneously express mesenchymal cell markers, such as vimentin $(99.9 \pm 0.1 \%, \mathrm{n}=6)$, fibronectin $(73.3 \pm 0.1 \%, \mathrm{n}=2)$ and $\alpha$-SMA $(100 \pm 0 \%, \mathrm{n}=6)$ (figure E2). This allows us to define tissue fibrocytes as $\mathrm{CD}_{4} 5^{+} \mathrm{FSP} 1^{+}$cells. These cells were identified by immunohistochemistry as shown in figure 1 , and they were detected in distal tissue specimens from 11 out of 12 COPD patients (92\%) and 13 out of 20 control subjects (65\%) (figure 2), as well as in proximal tissue specimens from 14 out of 14 COPD patients (100\%) and 16 out of 21 control subjects (76\%) (figure 3 ).

These fibrocytes were located in the subepithelial region of both distal and proximal airways (figures $2 \mathrm{a}$ and 3a), and occasionally within the epithelial layer. No $\mathrm{CD}_{4} 5^{+} \mathrm{FSP} 1^{+}$cells were evident within the airway smooth muscle layer. Some tissue fibrocytes were found in the peribronchial area outside the smooth muscle layer (figure E3). However, the analysis of fibrocyte density in this latter region could not be performed systematically since this area could not be identified in each of our tissue specimens. The density of bronchial fibrocytes was higher in the subepithelial region of distal airways of COPD patients (median 133 cells $\cdot \mathrm{mm}^{-2}\left(95 \%\right.$ CI $40-469$ cells $\cdot \mathrm{mm}^{-2}$ ), $\mathrm{n}=12$ ) than in that of control subjects (median $42 \mathrm{cells} \cdot \mathrm{mm}^{-2}$ (95\% CI 31-114 cells $\cdot \mathrm{mm}^{-2}$ ); $\mathrm{p}<0.05, \mathrm{n}=20$ ) (figure $2 \mathrm{~b}$ ). Similarly, fibrocyte density was also increased in the proximal airways of COPD patients (median 73 cells $\cdot \mathrm{mm}^{-2}$ (95\% CI $47-139$ cells $\cdot \mathrm{mm}^{-2}$ ), $\mathrm{n}=14$ ) compared with those of control subjects (median 21 cells $\cdot \mathrm{mm}^{-2}\left(95 \%\right.$ CI $18-60$ cells $\left.\cdot \mathrm{mm}^{-2}\right) ; \mathrm{p}<0.05, \mathrm{n}=21$ ) (figure $3 \mathrm{~b}$ ). In both distal and proximal airways, there was no difference in subepithelial areas considered for tissue fibrocyte quantification between COPD patients and control subjects (figures $2 \mathrm{c}$ and $3 \mathrm{c}$ ). Not surprisingly, however, the density of fibrocytes in the subepithelial area of the proximal tissue was positively and significantly correlated with that measured in the distal airways (figure E4). Since COPD has been described as a heterogeneous upper lobe predominant disease in subgroups of patients [2], we wondered whether fibrocytes specifically accumulated in the upper lobes. For distal and proximal tissue specimens, there was no significant difference in fibrocyte density between these two sites (figure E5a and b). Taking advantage of the various location of sample sites from transplant patients $(n=4)$, we also observed that fibrocyte density was not significantly different from upper to lower lobes in these patients (figure E5c). In both proximal and distal specimens, fibrocyte density remained significantly increased in COPD patients compared with control smokers when the never-smoker control subjects were removed from the analysis (figure E6). To account for the sex differences between COPD patients and control subjects, we performed 


\begin{tabular}{|c|c|c|c|}
\hline & COPD & Control & p-value \\
\hline Subjects & 17 & 25 & \\
\hline Age years & $66.2 \pm 9.5$ & $61.7 \pm 8.1$ & 0.11 \\
\hline Male/female & $11 / 6$ & $5 / 20$ & 0.008 \\
\hline BMI $\mathrm{kg} \cdot \mathrm{m}^{-2}$ & $24.7 \pm 4.1$ & $26.5 \pm 6.9$ & 0.34 \\
\hline Current smoker yes/no & $2 / 15$ & $10 / 15$ & 0.09 \\
\hline Ex-smoker yes/no & $15 / 2$ & $8 / 17$ & 0.0004 \\
\hline Smoking history pack-years & $43.7 \pm 22.8$ & $18.1 \pm 16.8$ & 0.0007 \\
\hline \multicolumn{4}{|l|}{ Lung function tests } \\
\hline FEV $1 \%$ pred & $57.2 \pm 22.5$ & $100.0 \pm 16.7$ & $<0.0001$ \\
\hline $\mathrm{FEV}_{1} / \mathrm{FVC} \%$ & $53.2 \pm 16.3$ & $78.0 \pm 8.0$ & $<0.0001$ \\
\hline FVC \% pred & $82.0 \pm 15.4$ & $107 \pm 15.8$ & $<0.0001$ \\
\hline RV \% pred & $168 \pm 68.8$ & $112 \pm 27.8$ & 0.0007 \\
\hline TLCo \% pred & $53.4 \pm 22.6$ & $81.8 \pm 20.4$ & 0.0003 \\
\hline 6-min walk test distance $\mathrm{m}$ & $472 \pm 67$ & $503 \pm 69$ & 0.19 \\
\hline \multicolumn{4}{|l|}{ Arterial blood gases } \\
\hline $\mathrm{PaO}_{2} \mathrm{mmHg}$ & $78.0 \pm 11.2$ & $85.1 \pm 13.2$ & 0.08 \\
\hline $\mathrm{PaCO}_{2} \mathrm{mmHg}$ & $40.7 \pm 7.7$ & $35.7 \pm 2.8$ & 0.01 \\
\hline \multicolumn{4}{|l|}{ CT parameters } \\
\hline \multicolumn{4}{|l|}{ Bronchi } \\
\hline $\mathrm{WA}_{4} \%$ & $4.2 \pm 0.4$ & $3.8 \pm 0.6$ & 0.06 \\
\hline $\mathrm{WT}_{4} \mathrm{~mm}$ & $1.7 \pm 0.2$ & $1.5 \pm 0.2$ & 0.03 \\
\hline WA $5 \%$ & $4.2 \pm 0.4$ & $3.2 \pm 0.4$ & $<0.0001$ \\
\hline WT5 mm & $1.5 \pm 0.2$ & $1.3 \pm 0.2$ & 0.02 \\
\hline \multicolumn{4}{|l|}{ Emphysema } \\
\hline LAA \% & $21.9 \pm 16.6$ & $4.2 \pm 4.0$ & $<0.0001$ \\
\hline Emphysema" yes/no & $12 / 5$ & $3 / 22$ & 0.0002 \\
\hline \multicolumn{4}{|l|}{ Air trapping } \\
\hline MLA E HU & $-858 \pm 23$ & $-817 \pm 38$ & 0.002 \\
\hline MLA I HU & $-865 \pm 24$ & $-821 \pm 33$ & 0.0001 \\
\hline MLA I-E HU & $-7.5 \pm 12$ & $-7.7 \pm 31$ & 0.52 \\
\hline \multicolumn{4}{|l|}{ Pulmonary vessels } \\
\hline$\% \mathrm{CSA}<5$ & $0.35 \pm 0.10$ & $0.54 \pm 0.20$ & 0.0003 \\
\hline$\%$ CSA5-10 & $0.11 \pm 0.02$ & $0.15 \pm 0.04$ & 0.0008 \\
\hline $\mathrm{CSN}<5$ & $0.28 \pm 0.03$ & $0.47 \pm 0.19$ & 0.0004 \\
\hline CSN5-10 & $0.016 \pm 0.004$ & $0.023 \pm 0.006$ & 0.0008 \\
\hline
\end{tabular}

Data are presented as $\mathrm{n}$ or mean $\pm \mathrm{SD}$, unless otherwise stated. $\mathrm{BMI}$ : body mass index; FEV1: forced expiratory volume in $1 \mathrm{~s}$; FVC: forced vital capacity; RV: residual volume; TLCo: transfer factor of the lung for carbon monoxide; $\mathrm{PaO}_{2}$ : arterial oxygen tension; $\mathrm{PaCO}_{2}$ : arterial carbon dioxide tension; $\mathrm{CT}$ : computed tomography; WA4/5\%: mean wall area percentage at the fourth/fifth generation; WT4/5: wall thickness at the fourth/fifth generation; LAA: low-attenuation area; MLA E or I: mean lung attenuation value during expiration (E) or inspiration (I); MLA I-E: difference between inspiratory and expiratory mean lung attenuation value; $\% \mathrm{CSA}<5$ : percentage of total lung area taken up by the cross-sectional area of pulmonary vessels $<5 \mathrm{~mm}^{2}$; \%CSA5-10: percentage of total lung area taken up by the cross-sectional area of pulmonary vessels $5-10 \mathrm{~mm}^{2}$; CSN $<5$ : number of vessels $<5 \mathrm{~mm}^{2}$ normalised by total lung area; CSN510: number of vessels $5-10 \mathrm{~mm}^{2}$ normalised by total lung area. ${ }^{\#}$ : emphysema defined as $L A A \%>10 \%$. $\mathrm{p}$-values were calculated with the use of a two-sided independent t-test for variables with a parametric distribution, Fisher's exact test for comparison of proportions and the Mann-Whitney U-test for comparison of nonparametric variables.

another subgroup analysis in sex- and age-matched patients. Consequently, the sex ratios were identical ( $50 \%$ in both subgroups). Fibrocyte density in the proximal, but not distal, tissue remained significantly higher in COPD patients than matched control subjects (figure E7a and b).

To further confirm our results, we co-stained FSP1 with CD3 or CD19 to determine whether FSP1 ${ }^{+}$cells could be T-lymphocytes or B-lymphocytes, respectively. Except for one control subject, very few $\mathrm{CD}^{+}$cells also expressed FSP1 (figure E8a), and there was no significant difference in the density of $\mathrm{CD}^{+} \mathrm{FSP}^{+}$cells in the subepithelial region of the distal airways between controls and COPD patients (figure E8b and c). Similarly, this density in the proximal airways was not significantly different between the groups (figure E8d and e). The B-lymphocyte CD19 marker co-localised with $\mathrm{FSP}^{+}$cells neither in distal (figure E9a) nor in 

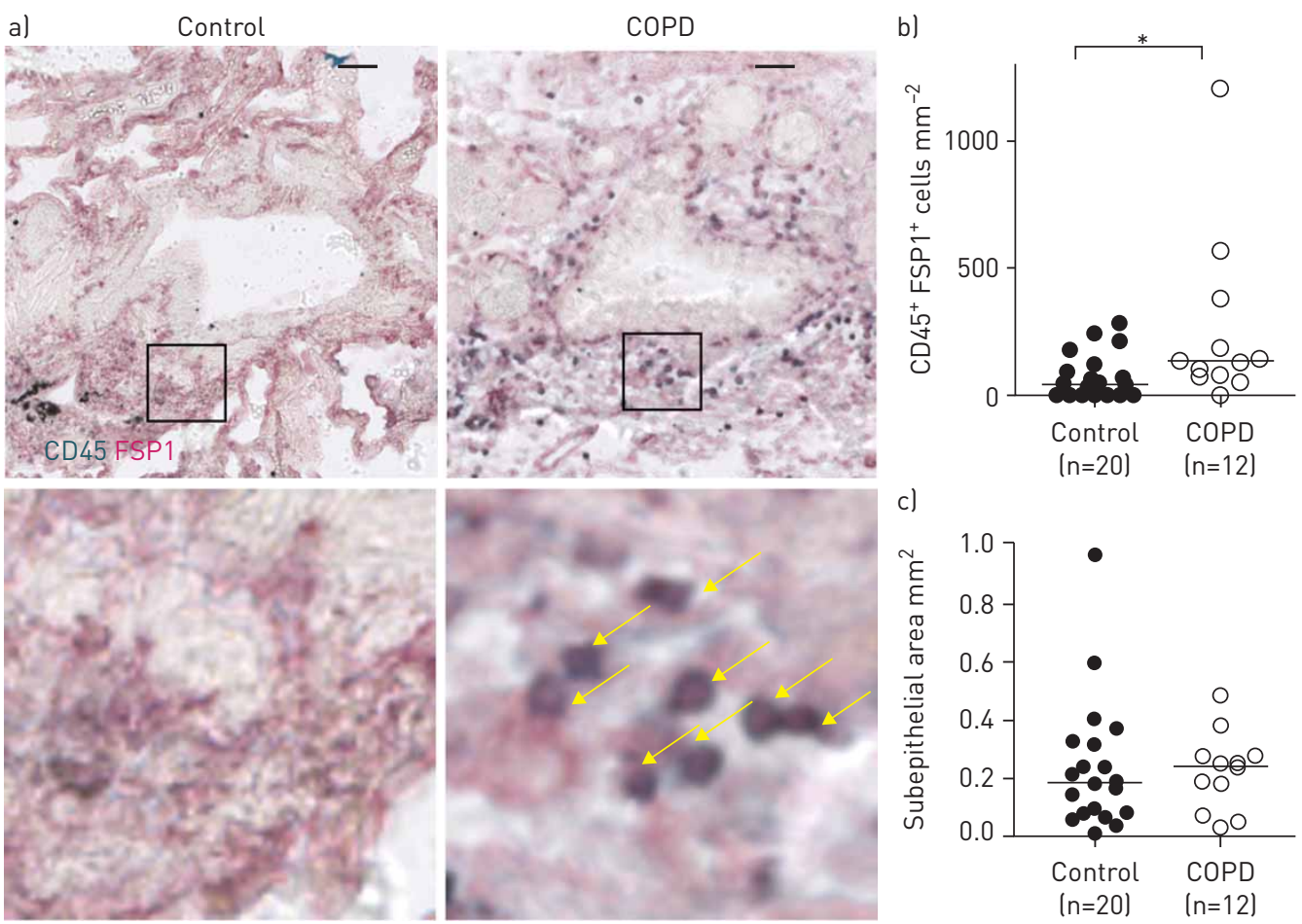

FIGURE 2 Increased fibrocyte density in distal airways of COPD patients. FSP1: fibroblast-specific protein 1. a) Representative staining of CD45 (green) and FSP1 (red) in distal bronchial tissue specimens from a control subject and a COPD patient. The yellow arrows indicate fibrocytes, defined as $\mathrm{CD} 45^{+} \mathrm{FSP} 1^{+}$cells. Higher magnification images are shown in the bottom row. Scale bar: $50 \mu \mathrm{m}$. b) Quantification of fibrocyte density (normalised by the subepithelial areal in one specimen/patient. *: $p<0.05$, Mann-Whitney test. c) Comparison of the subepithelial areas in control subjects and COPD patients. b, c) Medians are represented as horizontal lines.

proximal (figure E9b) tissue specimens. We also co-immunostained CD34 and FSP1. CD $34^{+} \mathrm{FSP}^{+}$cells were detected in distal tissue specimens from only two out of 12 COPD patients (17\%) and four out of 20 control subjects $(20 \%)$ (figure E10). $\mathrm{CD}^{+} 4^{+} \mathrm{FSP}^{+}$cells were found in proximal tissue specimens from nine out of 13 COPD patients (69\%) and 11 out of 21 control subjects (52\%) (figure E11), but the density of these cells in COPD patients (median 0.5 cells $\cdot \mathrm{mm}^{-2}\left(95 \%\right.$ CI $\left.0.1-1.7 \mathrm{cells} \cdot \mathrm{mm}^{-2}\right), \mathrm{n}=13$ ) was very low compared with that of $\mathrm{CD}^{+} 5^{+} \mathrm{FSP}^{+}$cells (median 73 cells $\cdot \mathrm{mm}^{-2}$ (95\% CI $47-139$ cells $\cdot \mathrm{mm}^{-2}$ ), n=14) (figure $2 \mathrm{~b}$ ). In both distal and proximal airways, there was no difference in the density of $\mathrm{CD} 34^{+} \mathrm{FSP}^{+}$cells between COPD patients and control subjects (figures E10 and E11).

\section{Relationships between bronchial fibrocyte density and functional and CT parameters}

We determined the univariate correlation coefficients between the density of tissue fibrocytes in the subepithelial region of both distal and proximal airways and various functional and CT parameters, without correcting for multiple testing (tables E2 and E3). In the distal tissue specimens, the density of fibrocytes was negatively correlated with the FEV1/FVC ratio (figure $4 \mathrm{a}$ ) and positively correlated with arterial carbon dioxide tension $\left(\mathrm{PaCO}_{2}\right)$ (figure $4 \mathrm{~b}$ ). The density of tissue fibrocytes was also significantly associated with the mean lung attenuation value during exhalation (figure $4 \mathrm{c}$ ). In the proximal tissue specimens, the density of fibrocytes was negatively correlated with FEV1 (figure 4d) and FVC (table E2), and positively correlated with RV (table E2), wall thickness at the fourth and fifth generation (figure $4 \mathrm{e}$ and f), and wall area percentage at the fourth generation (table E2). Moreover, we observed identical key correlations when the never-smoker control subjects were removed from the analysis (figure E12). Again, considering sex differences between COPD patients and control subjects, we determined key correlation coefficients in a subgroup analysis of sex- and age-matched patients. All key correlations previously found in the whole population remained significant, except for the relationship between distal fibrocyte density and $\mathrm{PaCO}_{2}$ (figure E7c-h).

ROC curves were built for all subjects whose density of tissue fibrocytes was assessed in distal ( $\mathrm{n}=12$ COPD patients and 20 control subjects; figure 5a) and proximal $(n=14$ COPD patients and 21 control subjects; figure 5b) tissue specimens with significant areas under the curves (table 2). To predict COPD, the density of fibrocytes in the distal airways had a sensitivity of $83 \%$ and a specificity of $70 \%$, whereas this 
a)
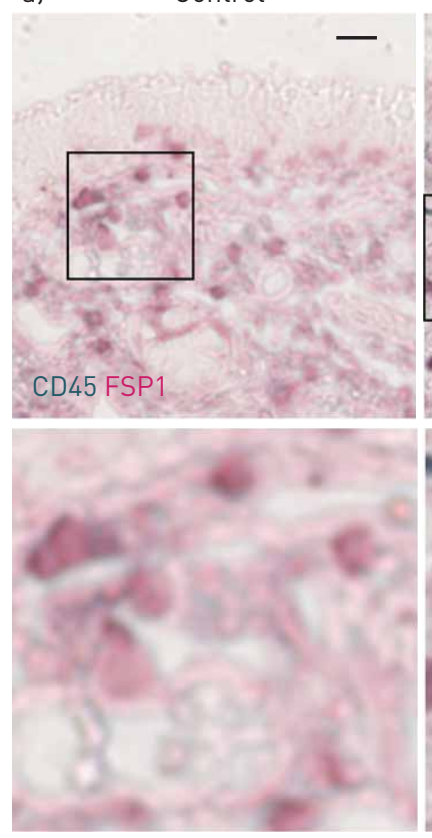

Control
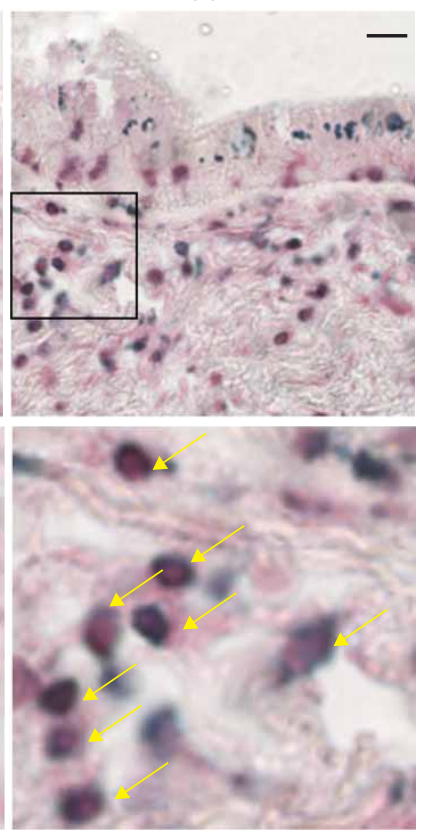

b)
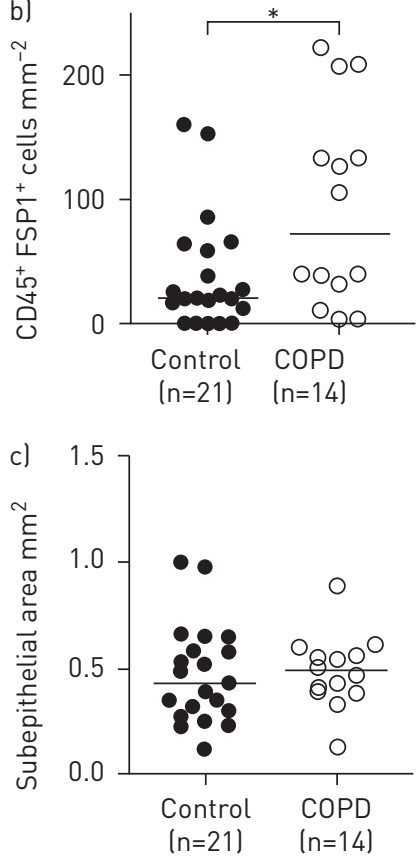

FIGURE 3 Increased fibrocyte density in the proximal airways of COPD patients. FSP1: fibroblast-specific protein 1. a) Representative staining of CD45 (green) and FSP1 (red) in proximal bronchial tissue specimens from a control subject and a COPD patient. The yellow arrows indicate fibrocytes, defined as CD $45^{+} \mathrm{FSP} 1^{+}$ cells. Higher magnification images are shown in the bottom row. Scale bar: $50 \mu \mathrm{m}$. b) Quantification of fibrocyte density (normalised by the subepithelial areal in one specimen/patient. *: $p<0.05$, Mann-Whitney test. c) Comparison of the subepithelial areas in control subjects and COPD patients. b, c) Medians are represented as horizontal lines.

density had a sensitivity of $79 \%$ and a specificity of $67 \%$ in the proximal airways (table 2). Moreover, the negative predictive value to eliminate COPD was $97.5 \%$ and $96.6 \%$ for the distal and proximal airways, respectively, using a prevalence of $10 \%$ for COPD in the general population [25]. ROC analyses allowed us to select the optimal value of fibrocyte density (cut-off values of 72 and $32 \mathrm{CD} 45^{+} \mathrm{FSP}^{+} \mathrm{cells}^{\mathrm{mm}} \mathrm{m}^{-2}$ for distal and proximal tissue, respectively) to classify patients either with a high or low level of tissue fibrocytes (table 2). COPD was associated with a high density of fibrocytes in distal (OR 11.7 (95\% CI 1.9-70.2); $\mathrm{p}<0.05)$ and proximal (OR $7.3(95 \%$ CI $1.5-35.1) ; \mathrm{p}<0.05)$ airways. Thus, a high tissue fibrocyte density is associated with an increased risk of COPD.

\section{Circulating fibrocytes are unchanged in stable COPD}

The percentage of blood fibrocytes $\left(\mathrm{CD} 45^{+}\right.$collagen $\mathrm{I}^{+}$cells) in PBMCs was not significantly different between stable COPD patients (median 10.3\% (95\% CI 4.6-16.5\%) of PBMCs, $n=12$ ) and control subjects (median $7.9 \%$ (95\% CI 4.1-11.6\%) of PBMCs, $\mathrm{n}=22$ ) (figure E13a). A similar result was obtained when the fibrocyte concentration was expressed as absolute counts per millilitre of blood (data not shown). Finally, the percentage of blood fibrocytes (i.e. $\mathrm{CD}_{4} 5^{+}$collagen $\mathrm{I}^{+}$cells) in PBMCs was significantly correlated with the density of bronchial fibrocytes (i.e. $\mathrm{CD}_{4} 5^{+} \mathrm{FSP} 1^{+}$cells) in the distal airways (figure E13b).

\section{COPD epithelial supernatant favours fibrocyte survival}

We next investigated whether secretions from BECs from control or COPD patients could affect fibrocyte viability in an in vitro assay. We evaluated this effect using BECs obtained from lung resection material sampled either in control subjects $(n=2)$ or in COPD patients $(n=2)$ (table E5), cultured at the air-liquid interface. Fibrocytes were cultured from blood samples from a separate cohort of six COPD patients (table E6). Between 7 and 10 days after blood sampling, cells, almost all of which were CD45 ${ }^{+}$FSP $1^{+}$ (94.9 $\pm 3.6 \%)$, were exposed for 7 days to a mixture of fully differentiated BEC supernatants derived either from control subjects or COPD patients. At 7 days after initial exposure, the level of CD $45^{+} \mathrm{FSP} 1^{+}$cells remained high $(92.9 \pm 3.9 \%$ and $93.4 \pm 3.3 \%$ for the control and COPD conditions, respectively). However, exposure of fibrocytes to COPD epithelial supernatant significantly decreased the percentage of dying cells (figure E14). 

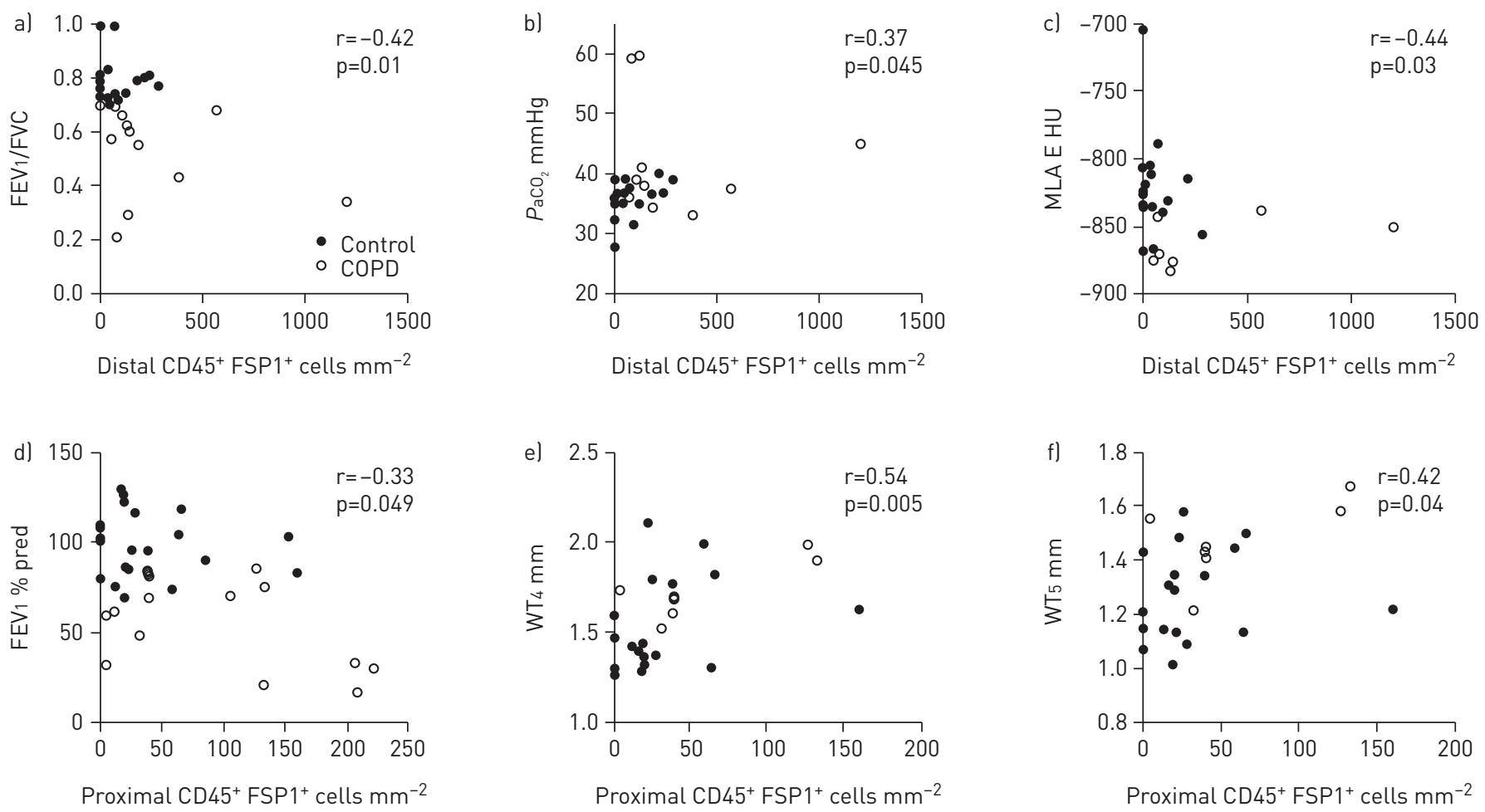

FIGURE 4 Relationships between fibrocyte density, lung function parameters and computed tomography parameters. FSP1: fibroblast-specific protein 1; FEV1: forced expiratory volume in $1 \mathrm{~s} ; \mathrm{FVC}$ : forced vital capacity; $\mathrm{PaCO}_{2}$ : arterial carbon dioxide tension; MLA E: mean lung attenuation value during expiration; WT4/5: wall thickness at the fourth/fifth generation. a-c) Relationships between a) $\left.\mathrm{FEV}_{1} / \mathrm{FVC}, \mathrm{b}\right) \mathrm{PaCO}_{2}$ and $\mathrm{c}$ ) $\mathrm{MLA}_{\mathrm{E}} \mathrm{E}$ and the density of $\mathrm{CD}_{4} 5^{+} \mathrm{FSP} 1^{+}$cells in distal airways measured in control subjects and COPD patients. d-f) Relationships between d) FEV 1 , e) WT4 and f) WT5 and the density of $\mathrm{CD}_{4} 5^{+} \mathrm{FSP} 1^{+}$cells in proximal airways measured in control subjects and COPD patients. The correlation coefficient ( $r$ ) and significance level ( $\mathrm{p}$-value) were obtained by using nonparametric Spearman analysis.

\section{Discussion}

In the present study, we have shown that the density of tissue fibrocytes (i.e. $\mathrm{CD} 45^{+} \mathrm{FSP} 1^{+}$cells) is significantly greater in both distal and proximal airway specimens of COPD patients compared with that of control subjects. We also found a significant correlation between this tissue fibrocyte density and blood fibrocytes as well as airway obstruction, increased wall thickness or air trapping. Using ROC curve analysis and univariate logistic regression analysis, we observed that a high density of tissue fibrocytes increases the likelihood of COPD. Finally, it appears that fibrocyte survival is increased by epithelial cell secretions from
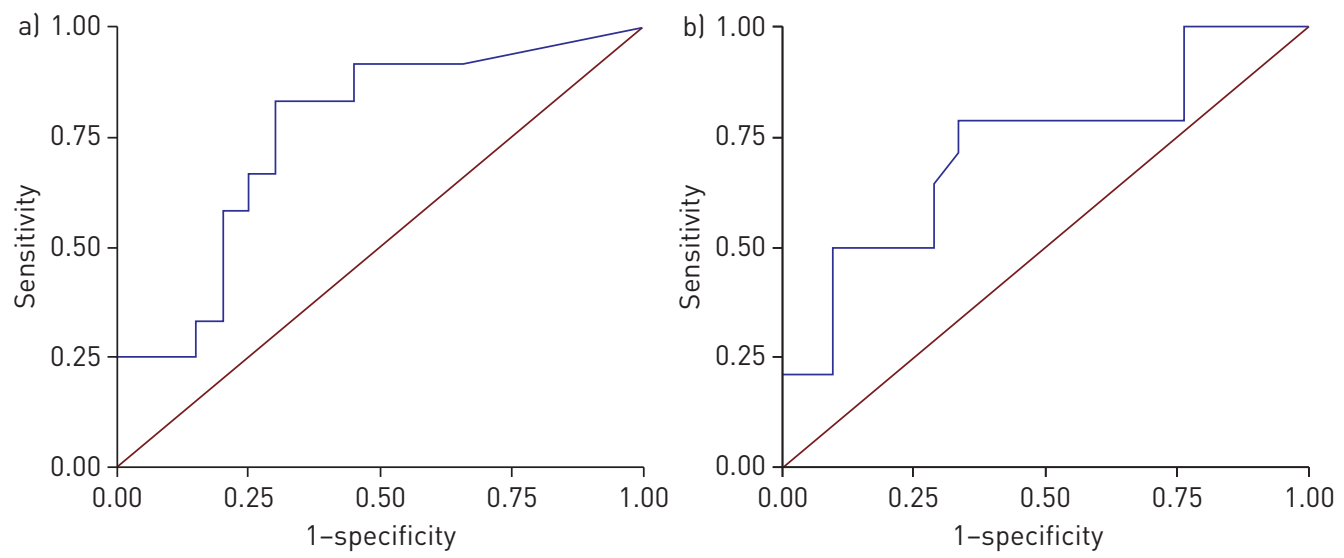

FIGURE 5 Diagnosis accuracy of high fibrocyte density for chronic COPD: receiver operating characteristic curves for control subjects and COPD patients with fibrocyte density measured in al distal or b) proximal tissue specimens were built to predict COPD. 


\begin{tabular}{|c|c|c|c|c|c|c|}
\hline $\begin{array}{l}\text { Type of } \\
\text { tissue }\end{array}$ & Specimens & AUC & p-value & $\begin{array}{l}\text { Cut-off value } \mathrm{CD} 45^{+} \\
\mathrm{FSP}^{+} \text {cells: } \mathrm{mm}^{-2}\end{array}$ & $\begin{array}{l}\text { Sensitivity } \\
(95 \% \mathrm{CI})\end{array}$ & $\begin{array}{l}\text { Specificity } \\
(95 \% \mathrm{CI})\end{array}$ \\
\hline Distal & 32 & $0.76 \pm 0.09$ & 0.04 & 72 & $0.83(0.70-0.96)$ & $0.70(0.54-0.86)$ \\
\hline Proximal & 35 & $0.72 \pm 0.09$ & 0.02 & 32 & $0.79(0.65-0.92)$ & $0.67(0.51-0.82)$ \\
\hline
\end{tabular}

Data are presented as $\mathrm{n}$ or means $\pm \mathrm{SD}$, unless otherwise stated. AUC: area under the curve. $\mathrm{p}$-values, sensitivity and specificity were evaluated for the receiver operating characteristic curve analysis.

COPD patients, a mechanism that could contribute to the elevated subepithelial density of fibrocytes in COPD patients.

There is a discrepancy between the present results and those previously obtained by WRIGHT et al. [13], which deserves some methodological discussion. WRIGHT et al. [13] did not find an increased level of tissue fibrocytes in COPD patients. They did not even observe any fibrocytes in distal airways. However, the methodology of tissue fibrocyte assessment and, ultimately, the definition of fibrocytes differed in the present study and in that of WRIGHT et al. [13]. WRIGHT et al.'s [13] method relied on the identification of CD34 and collagen I staining on sequential, instead of identical, sections, which could lead to either false fibrocyte identification because of apparent coexpression in closely apposed but not identical cells or fibrocyte underestimation because of the absence of coexpression in cells that are present only in one section. We have carefully addressed this issue by using antibodies and chromogens that are compatible with co-immunostaining in the same section. We have thus developed an image analysis technique that unambiguously identifies fibrocytes. Moreover, defining tissue fibrocytes as CD34 ${ }^{+}$collagen $\mathrm{I}^{+}$cells [13] may lead to fibrocyte underestimation, which is consistent with previous data showing a downregulation of CD34 expression when fibrocytes differentiate in culture [14]. With regard to the connection, the present data confirming the very low density of $\mathrm{CD} 34^{+} \mathrm{FSP} 1^{+}$cells in bronchial specimens are thus consistent with those of Wright et al. [13]. Fibrocytes are commonly defined as cells co-expressing CD45 and collagen I [26]. The expression of a haematopoietic marker, such as CD45, is one of the minimum criteria for fibrocyte identification and was used in the present study [26]. However, since immunohistochemistry for collagen I failed to unambiguously identify collagen $\mathrm{I}^{+}$cells in our experiments (data not shown), as well as in another report [27], we therefore used the FSP1 marker as a co-marker with CD45 for fibrocyte identification, as previously extensively described [15-18]. FSP1, also known as S100A4, is used as a marker for lung fibroblasts $[27,28]$. Most pulmonary FSP1 ${ }^{+}$cells express collagen I and the number of FSP1 ${ }^{+}$cells correlates with the extent of lung fibrosis in a murine model of fibrosis, suggesting that these cells contribute to collagen deposition $[27,29]$. In addition, we have shown that almost all the $\mathrm{CD}_{4} 5^{+} \mathrm{FSP} 1^{+}$cells purified from circulating PBMCs also express collagen I, as well as mesenchymal cell markers, such as vimentin, fibronectin and $\alpha$-SMA, after 14 days of differentiation in vitro (figure E2), which is consistent with the definition of the fibrocyte as a myofibroblast precursor, as previously described $[11,14,30]$. It thus appears that the term tissue fibrocyte is more accurate for CD45 and FSP1 double-positive cells. Since FSP1 expression was initially identified in fibroblasts [28], but was subsequently characterised in immune cells such as T- and B-lymphocytes [15], we paid special attention to co-immunostaining of FSP1 with CD3 or CD19. In doing so, we showed that T-lymphocytes co-expressing CD3 and FSP1 represented only a minor subset of $\mathrm{CD}_{4} 5^{+} \mathrm{FSP}^{+}$cells, the density of which did not change in COPD patients. We also showed that no B-lymphocytes co-expressing CD19 and FSP1 were present in either distal or proximal human bronchi from both control subjects and COPD patients. Finally, FSP1 expression has also been characterised in macrophages [29]. However, numerous macrophage markers, such as CD68, CD163, CD204, CD206 and CD209, are also expressed by fibrocytes [31-33]. It is thus impossible to properly differentiate fibrocytes from macrophages using immunohistochemistry even if collagen $\mathrm{I}^{+} \mathrm{CD} 45^{+}$double staining was suitable.

Our results may support a potential role for tissue fibrocytes in COPD. Indeed, the greater the density of bronchial fibrocytes, the lower the FEV1 value or the FEV1/FVC ratio. Similarly, the greater the density of bronchial fibrocytes, the greater the bronchial wall thickness or the pulmonary air trapping. Although the association between fibrocyte presence and the alteration of lung function combined with anatomical modifications suggests a deleterious effect of fibrocytes, we would like to emphasise that the association does not demonstrate that these cells play a causative role herein. We previously pointed out a potential detrimental role of blood fibrocytes, since a high concentration of fibrocytes in the peripheral circulation of COPD patients during an acute exacerbation was associated with a higher mortality [12]. Moreover, blood fibrocytes were present at a high level in frequently exacerbating patients [12]. Since small airways are the major site of airway obstruction in COPD [34-37], the observation that tissue fibrocyte density, 
assessed in the present study, was higher in distal than in proximal airways makes sense. The correlation between the concentration of circulating fibrocytes and the density of distal bronchial fibrocytes may indicate that fibrocytes, which are recruited in the blood during an acute exacerbation [12], subsequently migrate to the airways and could participate in the tissue repair and remodelling processes. Indeed, once recruited to the lungs, fibrocytes may play various roles, including matrix secretion and degradation, pro-fibrotic cytokine production, and activation of contractile force [38]. The presence of fibrocytes in the lungs of patients affected with asthma and idiopathic pulmonary fibrosis suggests a physiological repair response in several types of lung damage [14, 39, 40,41]. On the one hand, this repair process should spontaneously resolve with time and should disappear with tobacco smoking cessation. On the other hand, a switch to aberrant repair or to excessive degradation may participate in abnormal remodelling processes, such as peribronchial fibrosis and emphysema. The reduced cell death in fibrocytes cultured with BECs from COPD patients, detected by the single $\mathrm{PI}^{+}$method, combined with the elevated density of fibrocytes at the proximity of the epithelium in tissue samples from COPD patients, suggests that secretions from epithelial cells in the COPD microenvironment provide pro-survival signals for tissue fibrocytes and could explain, at least partially, the bronchial accumulation of fibrocytes in COPD patients. Whether fibrocyte persistence in COPD patients participates in aberrant repair processes and chronic inflammation is still under investigation. The specific role of fibrocytes in COPD pathogenesis remains another open question. Specific physical and chemical signals originating from the microenvironment are likely to play a key role in regulating fibrocyte final localisation, differentiation and function inside the tissue [38].

In light of the important sex differences observed in COPD patients [42], as well as in COPD mouse models [43], we tested whether our results reflect sex differences. Matching the patients by sex suggested that our results are not related to sex-related features. The question of fibrocyte participation in sex-related differences in the clinical expression of COPD between males and female remains to be properly addressed in future studies that are appropriately powered for sex analysis.

The present study has some limitations, which deserve further comments. Additional studies are required to explore the cellular and molecular mechanisms involved in epithelium-dependent fibrocyte survival. Continuous efforts are warranted to clarify the cellular mechanisms by which fibrocytes participate in obstruction development. The specimens for fibrocyte detection were obtained from patients with a diagnosis of lung cancer in 37 out of 42 patients. As FSP1 is often expressed in malignant cells [44, 45], one may suggest that it could have an impact on the fibrocyte density measured in our study. Since 1) bronchial specimens for fibrocyte analysis were selected from macroscopically normal lung resection material and 2) patients with a staging different from pN0 confirmed after surgery were excluded, it is unlikely that malignancy was sufficient to explain the increase in fibrocyte density we observed in COPD patients.

In conclusion, by taking advantage of unambiguous fibrocyte identification by co-immunostaining and image analysis, we show that COPD patients exhibit a greater density of fibrocytes in distal and proximal airways than control subjects. A high density of tissue fibrocytes is associated with lower lung function, airway structural changes and a higher risk of COPD, underlying the need for further studies to investigate the physiological and pathophysiological functions of fibrocytes.

Acknowledgements: We thank the study participants and the staff of the Thoracic Surgery, Radiology, Pathology, Respiratory and Lung Function Testing departments from the University Hospital of Bordeaux (Bordeaux, France), Virginie Niel (CIC 1401, Bordeaux, France) for technical assistance, and the Bordeaux Imaging Centre (BIC; Bordeaux, France) for help with imaging and image analysis. Microscopy was performed at BIC, a service unit of the CNRS-INSERM and Bordeaux University, a member of the national BioImaging infrastructure of France supported by the French National Research Agency (ANR-10-INBS-04). The help of Christel Poujol, Sébastien Marais and Fabrice Cordelières (BIC) for imaging, the help of Muriel Cario-André (U1035 INSERM, Université Bordeaux, Bordeaux, France) for immunohistochemistry, and the help of Pierre Vallois (Université de Lorraine, Institut Elie Cartan de Lorraine, UMR 7502, Vandoeuvre-lès-Nancy, France) for statistics is acknowledged.

Conflict of interest: I. Dupin reports grants from Fondation Bordeaux Université, during the conduct of the study. In addition, she has a patent (EP 15152886.6: New compositions and methods of treating and/or preventing Chronic Obstructive Pulmonary Disease) pending. M. Thumerel has nothing to disclose. E. Maurat has nothing to disclose. F. Coste has nothing to disclose. E. Eyraud has nothing to disclose. H. Begueret has nothing to disclose. T. Trian has nothing to disclose. M. Montaudon has nothing to disclose. R. Marthan has nothing to disclose. P-O. Girodet reports personal fees from Novartis, Chiesi, Boehringer Ingelheim, AstraZeneca and GlaxoSmithKline, outside the submitted work. In addition, he has a patent (EP 15152886.6: New compositions and methods of treating and/or preventing Chronic Obstructive Pulmonary Disease) pending. P. Berger reports grants from Nycomed, Takeda and Fondation du Souffle-Fonds de dotation Recherche en Santé Respiratoire, during the conduct of the study; grants and personal fees from Novartis, personal fees and nonfinancial support from AstraZeneca, Sanofi, and Chiesi, grants, personal fees and nonfinancial support from Boehringer Ingelheim, and personal fees from Menarinni and Teva, outside the submitted work. In addition, he has a patent (EP 15152886.6: New compositions and methods of treating and/or preventing Chronic Obstructive Pulmonary Disease) pending. 
Support statement: This study was sponsored and supported by Bordeaux University Hospital (CHU de Bordeaux). This study was supported by a grant from the Fondation Bordeaux Université, with funding from Assistance Ventilatoire à Domicile (AVAD) and Fédération Girondine de Lutte contre les Maladies Respiratoires (FGLMR). Funding information for this article has been deposited with the Crossref Funder Registry.

\section{References}

1 Hogg JC, Chu F, Utokaparch S, et al. The nature of small-airway obstruction in chronic obstructive pulmonary disease. N Engl J Med 2004; 350: 2645-2653.

2 Global Initiative for Chronic Obstructive Lung Disease. Global Strategy for the Diagnosis, Management, and Prevention of Chronic Obstructive Pulmonary Disease. 2019. https:/goldcopd.org/wp-content/uploads/2018/11/ GOLD-2019-v1.7-FINAL-14Nov2018-WMS.pdf Date last accessed: January 1, 2019.

3 Ko FW, Chan KP, Hui DS, et al. Acute exacerbation of COPD. Respirology 2016; 21: 1152-1165.

4 Soler-Cataluna JJ, Martinez-Garcia MA, Roman Sanchez P, et al. Severe acute exacerbations and mortality in patients with chronic obstructive pulmonary disease. Thorax 2005; 60: 925-931.

5 Calverley PM, Anderson JA, Celli B, et al. Salmeterol and fluticasone propionate and survival in chronic obstructive pulmonary disease. N Engl J Med 2007; 356: 775-789.

6 Tashkin D, Celli B, Senn S, et al. A 4-year trial of tiotropium in chronic obstructive pulmonary disease (UPLIFT trial). Rev Port Pneumol 2009; 15: 137-140.

7 Vestbo J, Anderson JA, Brook RD, et al. Fluticasone furoate and vilanterol and survival in chronic obstructive pulmonary disease with heightened cardiovascular risk (SUMMIT): a double-blind randomised controlled trial. Lancet 2016; 387: 1817-1826.

8 Wedzicha JA, Banerji D, Chapman KR, et al. Indacaterol-glycopyrronium versus salmeterol-fluticasone for COPD. N Engl J Med 2016; 374: 2222-2234.

9 Lipson DA, Barnhart F, Brealey $\mathrm{N}$, et al. Once-daily single-inhaler triple versus dual therapy in patients with COPD. N Engl J Med 2018; 378: 1671-1680.

10 Niewoehner DE, Kleinerman J, Rice DB. Pathologic changes in the peripheral airways of young cigarette smokers. N Engl J Med 1974; 291: 755-758.

11 Bucala R, Spiegel LA, Chesney J, et al. Circulating fibrocytes define a new leukocyte subpopulation that mediates tissue repair. Mol Med 1994; 1: 71-81.

12 Dupin I, Allard B, Ozier A, et al. Blood fibrocytes are recruited during acute exacerbations of chronic obstructive pulmonary disease through a CXCR4-dependent pathway. J Allergy Clin Immunol 2016; 137: 1036-1042.

13 Wright AK, Newby C, Hartley RA, et al. Myeloid-derived suppressor cell-like fibrocytes are increased and associated with preserved lung function in chronic obstructive pulmonary disease. Allergy 2017; 72: $645-655$.

14 Schmidt M, Sun G, Stacey MA, et al. Identification of circulating fibrocytes as precursors of bronchial myofibroblasts in asthma. I Immunol 2003; 171: 380-389.

15 Mitsuhashi A, Goto H, Saijo A, et al. Fibrocyte-like cells mediate acquired resistance to anti-angiogenic therapy with bevacizumab. Nat Commun 2015; 6: 8792

16 Sangaletti S, Tripodo C, Cappetti B, et al. SPARC oppositely regulates inflammation and fibrosis in bleomycin-induced lung damage. Am J Pathol 2011; 179: 3000-3010.

17 Rock JR, Barkauskas CE, Cronce MJ, et al. Multiple stromal populations contribute to pulmonary fibrosis without evidence for epithelial to mesenchymal transition. Proc Natl Acad Sci USA 2011; 108: E1475-E1483.

18 Aono Y, Kishi M, Yokota Y, et al. Role of platelet-derived growth factor/platelet-derived growth factor receptor axis in the trafficking of circulating fibrocytes in pulmonary fibrosis. Am J Respir Cell Mol Biol 2014; 51: 793-801.

19 Coste F, Dournes G, Dromer C, et al. CT evaluation of small pulmonary vessels area in patients with COPD with severe pulmonary hypertension. Thorax 2016; 71: 830-837.

20 Dournes G, Laurent F, Coste F, et al. Computed tomographic measurement of airway remodeling and emphysema in advanced chronic obstructive pulmonary disease. Correlation with pulmonary hypertension. Am J Respir Crit Care Med 2015; 191: 63-70.

21 Girodet PO, Dournes G, Thumerel M, et al. Calcium channel blocker reduces airway remodeling in severe asthma. A proof-of-concept study. Am J Respir Crit Care Med 2015; 191: 876-883.

22 Montaudon M, Berger P, de Dietrich G, et al. Assessment of airways with three-dimensional quantitative thin-section CT: in vitro and in vivo validation. Radiology 2007; 242: 563-572.

23 Trian T, Allard B, Dupin I, et al. House dust mites induce proliferation of severe asthmatic smooth muscle cells via an epithelium-dependent pathway. Am J Respir Crit Care Med 2015; 191: 538-546.

24 Rothman KJ. No adjustments are needed for multiple comparisons. Epidemiology 1990; 1: 43-46.

25 Halbert RJ, Natoli JL, Gano A, et al. Global burden of COPD: systematic review and meta-analysis. Eur Respir J 2006; 28: 523-532.

26 Reilkoff RA, Bucala R, Herzog EL. Fibrocytes: emerging effector cells in chronic inflammation. Nat Rev Immuno 2011; 11: 427-435

27 Lawson WE, Polosukhin VV, Zoia O, et al. Characterization of fibroblast-specific protein 1 in pulmonary fibrosis Am J Respir Crit Care Med 2005; 171: 899-907.

28 Strutz F, Okada H, Lo CW, et al. Identification and characterization of a fibroblast marker: FSP1. J Cell Biol 1995; 130: 393-405.

29 Inoue T, Plieth $\mathrm{D}$, Venkov CD, et al. Antibodies against macrophages that overlap in specificity with fibroblasts. Kidney Int 2005; 67: 2488-2493.

30 Phillips RJ, Burdick MD, Hong K, et al. Circulating fibrocytes traffic to the lungs in response to CXCL12 and mediate fibrosis. J Clin Invest 2004; 114: 438-446.

$31 \mathrm{Hu}$ X, DeBiasi EM, Herzog EL. Flow cytometric identification of fibrocytes in the human circulation. Methods Mol Biol 2015; 1343: 19-33.

32 Pilling D, Fan T, Huang D, et al. Identification of markers that distinguish monocyte-derived fibrocytes from monocytes, macrophages, and fibroblasts. PLoS One 2009; 4: e7475.

33 Bianchetti L, Barczyk M, Cardoso J, et al. Extracellular matrix remodelling properties of human fibrocytes. J Cell Mol Med 2012; 16: 483-495. 
34 Hogg JC, Macklem PT, Thurlbeck WM. Site and nature of airway obstruction in chronic obstructive lung disease. N Engl J Med 1968; 278: 1355-1360.

35 Hasegawa M, Nasuhara Y, Onodera Y, et al. Airflow limitation and airway dimensions in chronic obstructive pulmonary disease. Am J Respir Crit Care Med 2006; 173: 1309-1315.

36 Hogg JC, McDonough JE, Suzuki M. Small airway obstruction in COPD: new insights based on micro-CT imaging and MRI imaging. Chest 2013; 143: 1436-1443.

37 Hogg JC, Pare PD, Hackett TL. The contribution of small airway obstruction to the pathogenesis of chronic obstructive pulmonary disease. Physiol Rev 2017; 97: 529-552.

38 Dupin I, Contin-Bordes C, Berger P. Fibrocytes in asthma and chronic obstructive pulmonary disease: variations on the same theme. Am J Respir Cell Mol Biol 2018; 58: 288-298.

39 Nihlberg K, Larsen K, Hultgardh-Nilsson A, et al. Tissue fibrocytes in patients with mild asthma: a possible link to thickness of reticular basement membrane? Respir Res 2006; 7: 50.

40 Saunders R, Siddiqui S, Kaur D, et al. Fibrocyte localization to the airway smooth muscle is a feature of asthma. J Allergy Clin Immunol 2009; 123: 376-384.

41 Heukels P, van Hulst JAC, van Nimwegen M, et al. Fibrocytes are increased in lung and peripheral blood of patients with idiopathic pulmonary fibrosis. Respir Res 2018; 19: 90.

42 Jenkins CR, Chapman KR, Donohue JF, et al. Improving the management of COPD in women. Chest 2017; 151: 686-696.

43 Tam A, Churg A, Wright JL, et al. Sex differences in airway remodeling in a mouse model of chronic obstructive pulmonary disease. Am J Respir Crit Care Med 2016; 193: 825-834.

44 Ilg EC, Schafer BW, Heizmann CW. Expression pattern of S100 calcium-binding proteins in human tumors. Int $J$ Cancer 1996; 68: 325-332

45 Xue C, Plieth D, Venkov C, et al. The gatekeeper effect of epithelial-mesenchymal transition regulates the frequency of breast cancer metastasis. Cancer Res 2003; 63: 3386-3394. 